change their shape by a profound elongation. While some workers are inclined to lay greatest emphasis on the existence of sub-microscopic anisometric protein micelles in the cytoplasm; while others suggest that the main factors are located in an ectoplasm similar to that which we know is responsible for the cell-shape changes in echinoderm egg cell-divisions; Schmitt and his colleagues direct attention rather to the cell-surface itself. The evidence for the 'zip-fastener' theory of neurulation must be read in the original, but it is sure that the time has come for an intensive attack on the cell surfaces by colloid chemists familiar with the properties of interfacial protein and lipo-protein monolayers. The recent fundamental work of J. Holtfreter on 'tissue affinities' in morphogenesis looks in the same direction.

Doubtless the most remarkable article in the third symposium is that of K. B. Raper on the developmental patterns in the simple slime-moulds. The facts there reported appear nothing short of amazing to the specialist in better-known fields of morphological study. Slime-moulds had indeed been coming into the limelight through the curious experiments of A. R. Moore on the ability of their protoplasm to pass through very fine filters, but its destruction if forced through much coarser filter pores. But now Raper describes for the benefit of biologists accustomed to less startling material how myriads of myxamœbæ of wholly different spore origin and initially equal potentialities come together in enormous numbers, integrate themselves into a cooperative functioning whole, and afterwards differentiate along specific lines within prescribed limits to produce a single fructification. The article is well illustrated with photographs and drawings showing how the myxamœbæ stream together towards a central mass or peg, which then lifts itself up and differentiates into a highly complex and specifically characteristic sorocarp. Congregations of myxamobæ of different species move in to different centres. As if this behaviour were not enough, in some species the conjoined mass or "pseudoplasmodium" does a good deal of migration before it settles down and begins to differentiate. All these phenomena allow of much experimental analysis which has scarcely as yet been begun : the nature of the factors leading to aggregation, the mechanism of the movement of the pseudoplasmodia, and the factors governing differentiation of the sorocarp.

More familiar growth phenomena were not overlooked in the third symposium, however. A. F. Blakeslee gave a very interesting discussion of general growth patterns in plants, and heterogonic (allometric) growth problems in animals were well reviewed by A. H. Hersh. Finally, P. Weiss discussed the mechanics of nerve growth, dealing among other things with his 'deplantation' experiments, in which a piece of isolated nerve-cord and a detached limb are both implanted into the gelatinous connective tissue of the amphibian fin. Thus the gradual innervation of the limb and the spontaneous origination of rhythmical impulses from the nerve cord can be studied, as if in an elaborate form of tissue culture, subject only to the unavoidable endocrine environment of the host animal.

The above descriptions have not been able to do justice to more than a few of the admirable reviews in these symposia. By the time when this notice appears, the Fourth Symposium on Development and Growth, held at North Truro in August 1942, will be in course of publication. It was devoted to the general theme of the "Developmental Responses to Specific Chemical Agents" and included contributions by K. G. Stern on growth as a problem of chemical catalysis; E. L. Tatum on the relations between genes and growth hormones; E. J. Boell on the physiological and biochemical analysis of organizer action; P. R. White on developmental responses of isolated plant tissues; E. Allen on tissue growth and the sex hormones; F. C. McLean on ossification; O. A. Bessey on tissue responses to vitamin deficiencies; and A. J. Riker on pathological growth. It will certainly be as indispensable as the symposia which have preceded it.

If the present review serves to direct the attention of British experimental morphologists, in the widest sense of the term, to a series of conferences which are likely to remain for a long time the centre of these studies, and which, when the present troubles are over, may again unite biologists from both sides of the Atlantic, it will have achieved its purpose.

\section{TEACHING OF COLOUR IN SCHOOLS}

F DUCATIONAL reforms, large and small, are in the air. A great many people are taking advantage of the upheaval produced by the War to overhaul the existing educational machinery and to discover its weaknesses. Sometimes the material that is taught needs modernizing, sometimes it is the method of teaching that is wrong, sometimes there is a failure to arouse the latent interest and enthusiasm of a child in the fascinating natural phenomena that abound.

The subject of colour can occupy only a very small corner in the eurriculum of school or university, but the phenomena of colour are so intimately woven into the pattern of human experience that what is taught is worthy of the best possible presentation. It is not an easy subject since there are too many avenues of approach - the physicist will want to start from the spectrum, the physiologist from the retina, the psychologist from the sensation, the artist from the point of view of beauty and harmony-but at least it is to be hoped that one teacher will not be in conflict with another.

It was no doubt partly from high academic motives such as these that the Physical Society Colour Group interested itself in the teaching of colour, but the Group also has its own problems which in part arise from the very diverse instruction on colour which members of the Group have received in earlier days. Some of these problems are concerned with termino. logy, which is anything but uniform; some are concerned with more fundamental matters, in which the principles accepted almost as axioms by one group of workers are neither understood nor accepted by other groups. Nothing would be more welcome to technical workers in colour than that their subject should be taught in a generally approved and consistent manner from the nursery upwards.

Co-ordination and combined operations are familiar phrases in these days and they might well be applied to the meeting arranged by the Colour Group on September 11 at the Imperial College of Science and Technology. Mr. E. G. Savage, education officer of 
the London County Council, gave a lecture with many demonstrations on "The Teaching of Colour in Schools" to an audience drawn from members of the Group, themselves representing a number of different colour interests, but augmented by members of the Science Masters' Association and of the National Society of Art Masters. It is a fortunate circumstance that a person in Mr. Savage's position is so intensely interested in colour, and the success of the meeting was in part due to the instructional value of the lecture and in part due to the many different suggestions advanced during the discussion for a more sympathetic alignment of the views of the scientific worker and the artist.

The greatest cause for dispute arises from the fact that the man of science, especially the physicist, deals primarily with the additive mixture of coloured lights, while the artist deals with the additive mixture of paints and pigments, which unfortunately acts as a subtractive mixture of lights. A yellow pigment is yellow because it absorbs blue light, and the more blue it absorbs, the yellower it becomes. A mixture of paints acquires its final colour through the absorption, or subtraction, of different parts of the spectrum in varying degrees by the component pigments. There is nothing very difficult to understand about this, yet the child is so accustomed from his earliest days to mixing, or adding, paints together, that he quite naturally considers that he is adding colours together; hence the results of colour mixing are conceived in terms of the results of paint mixing. This leads to a number of contradictions of which the most outstanding is the perennial argument as to whether yellow is or is not a primary colour. In passing, it may be mentioned that the argument is not made less complex by the just claim of the psychologist to regard yellow as a pure sensation. This, however, is another issue which must not be confused with the immediate problem concerning the mixture of lights and the mixture of pigments.

If we mean by 'primary colour' a colour that cannot be reproduced from the mixture of any other colours, then the physicist may with the greatest of ease show that he can produce yellow by adding red and green lights together. The artist, on the other hand, will show that he can produce green by mixing blue and yellow, but in no circumstances can he get yellow by mixing any other pair of paints. The artist may legitimately refer to yellow as a primary pigment; but he is in error in referring to it as a primary colour. There need be little difficulty in reconciling the two approaches, were it not for the fact that a child is used to handling paints from a very tender age, many years before he learns anything about the spectrum; when at last he does hear about the spectrum and its absorption, he will almost certainly have something to unlearn about colour and colour mixing. Perhaps the only solution to the problem is to introduce the spectrum to the student at as early an age as possible.

The spectrum was the centre piece in Mr. Savage's lecture. One of the first fallacies to be exploded is the not unreasonable assumption that white is the simple colour, while reds, greens and blues are more complex. Having shown that, physically, white light can be split up into its spectral components by means of a prism, it should next be explained why natural objects, such as grass, should be coloured. It is not sufficient, in fact it is incorrect, to state that the light reflected from the surface of the grass becomes coloured green. The light first has to penetrate into the grass, be absorbed inside the medium and the remnant reflected back from surfaces within the grass itself, before any colouring occurs. The light reflected from the front surface is uncoloured, as can be demonstrated by observing the images formed by reflexion in the front and back surfaces of a piece of coloured glass. This introduces the conception of absorption, which may be demonstrated without dificulty by projecting a spectrum on to a screen and inserting a number of colour filters into the beam in turn. Several interesting features then appear-such, for example, that a yellow filter does not merely transmit the yellow band in the spectrum, but in general transmits the whole of the red-yellowgreen spectral region. Filters which show strong absorption are generally deep or saturated in colour, while those which show only slight absorption are desaturated or pale. In this way, by a series of experiments, it is possible to build up a general picture of the relation between the colours of objects as seen by the eye and the spectral composition of the light responsible for each colour.

When the physics of the problem has been grasped, it then becomes necessary to indicate that there are other factors at work ; that what we see depends not only on the light sent out but also on the eye that receives the light. The effect of contrast, of adaptation, of after-images can be demonstrated without much trouble and indeed with very striking results, but to the young student these phenomena must undoubtedly appear as complicated factors of a somewhat baffling nature. This is surely the point where the art master and the science master should be particularly careful not to cause confusion by overstressing the subjective aspect of colour on one hand or the physics of the problem on the other.

There are many other aspects that can be considered: the effect of various types of illuminant, the possibility of reproducing any colour by the appropriate mixture of red, green and blue lights, the application of additive and subtractive mixture to colour photography and to colour printing, the formation of coloured shadows, and so on. If the subject is properly handled, it can be made an admirable medium for the teaching, not only of the facts of colour, but also of general scientific principles, and for the development of a healthy scientific curiosity. Why is the sky blue? Why do we get a muddy brown or grey when we mix all the paints in a paint box together? How do flowers get their colour? Perhaps even some history can be taught as well. It was mentioned, for example, that it was due to the influence of Chevreul that the French exhibit in the 1851 Exhibition outclassed the British, so far as colour and colour harmony were concerned.

It was very gratifying to find such a cordial spirit among the different interests represented at the meeting and to discover that each appeared willing and anxious to learn from the other. A mechanism for securing effective co-operation has still to be worked out; the question of a text-book is one problem, an agreed terminology is another. $\mathrm{Mr}$. Savage has already contributed very greatly by the many lectures and demonstrations which he has given to groups of school teachers in various parts of Great Britain, and there is perhaps no better method of arriving at a consistent and acceptable doctrine of colour than through the missionary ardour he has revealed. 